\title{
EN TORNO A LAS SILVAS DE QUEVEDO
}

Dos motivaciones parecen haber confluido en este meritorio ensayo de crítica textual*. El primero, como dice Rocha en la p. 40, es el interés recientísimo (de 1972 para acá) por la silvas de Quevedo ${ }^{1}$; y el segundo, como dice en la p. 77, la necesidad, cada vez más visible, de una edición crítica de la poesía de Quevedo. Poniendo manos a la obra, y "como preparación y contribución hacia esa [esperable] edición monumental”, presenta ella una edición crítica de cinco silvas: A la Soberbia ("Esta que veis delante..."), Al Sueño (“¿Con qué culpa tan grave...?"), Al que cavaba una mina ("Diste crédito a un pino..."), Roma antigua y moderna ("Esta que miras grande Roma ahora...”) y A una nave (“¿Dónde vas, ignorante navecilla...?”).

El cap. 1, "Estado de la cuestión", reúne en orden cronológico cuantos datos se tienen sobre la persona de Quevedo y sobre Quevedo poeta, desde el siglo XVII hasta nuestros días. Es un panorama forzosamente esquemático, pero está sembrado de noticias bibliográficas casi exhaustivas ${ }^{2}$, y puede servir de guía para el interesado en la poesía de don Francisco.

* Francisco de Quevedo, Cinco Silvas, est., ed. y notas de María del Carmen Rocha de Sigler, Ediciones Universidad de Salamanca, 1994, 266 pp. ( Textos recuperados, 9).

${ }^{1}$ H. Ettinghausen, BRAE, 52 (1972), 211-284, llamó la atención sobre el importantísimo ms. XIV. E. 46 de la Bibl. Nazionale de Nápoles, donde hay 26 silvas de Quevedo. E. Asensio publicó en Edad de Oro, 2 (1983), 13-48, un estudio verdaderamente germinal, pues ha dado origen a otros varios (entre ellos uno mío, en el Homenaje a Asensio, 1988) sobre la historia y el significado del término silva y sobre las silvas de Quevedo.

${ }^{2}$ En la nota 12 dice Rocha, sin entrar en detalles, que algunas composiciones de Quevedo "circularon como anónimas en Romanceros y pliegos sueltos de la época", y en la nota 16 menciona ocho libros ajenos en cuyos preliminares hay versos de Quevedo. Hubiera sido mejor remitir a Astrana Marín, Verso (ed. 1943), pp. 1418 ss., donde estas noticias se dan en mayor abundancia. 
El cap. 2, "Concepto de silva" e "Inventario" de las silvas de Quevedo, es una delimitación del terreno. Según hizo ver Eugenio Asensio, la silva no fue siempre, o no fue sólo, lo que hoy entendemos por tal. A fines del siglo XVI no designaba un esquema métrico, sino cierto tipo de discurso poético ("azogada movilidad" de los sentimientos, transiciones súbitas, cambios de tono) que podía amoldarse a cualquier metro, por ejemplo octavas o tercetos. Los primeros españoles que escribieron silvas fueron imitadores de poetas italianos como Poliziano y Lorenzo de' Medici, que a su vez imitaron las Silvae de Estacio ${ }^{3}$. Pero muy pronto, hacia 1603, comenzó a ensayarse una nueva versificación, o sea el metro de silva (Espinosa, Rioja, Jáuregui), y en 1613 las Soledades de Góngora fijaron y consagraron el nuevo metro.

En cuanto a las silvas de Quevedo, unas son "estacianas" (en metros diversos) y otras son silvas en el sentido hoy habitual. Rocha toma en cuenta únicamente las 37 composiciones del "Índice" que imprimió Aldrete en Las tres Musas últimas (1670). Aunque cita varias veces mi artículo del Homenaje a Asensio, no ha atendido a la observación que allí hago (nota 3) sobre ese "Índice": no es de "Silvas", sino de "Silvas y Canciones", de manera que algunos de esos 37 poemas pudieran no ser "silvas" en la intención de Aldrete, sino "canciones" 4 . Por otra parte, el "Inventario" de Rocha no incluye las

${ }^{3}$ De estas silvas "estacianas", las muestras más antiguas que menciona Asensio son los ocho poemas así rotulados en la Poética silva ("manuscrito de Campomanes"), anterior a 1605. Pero la más antigua es seguramente la "Selva de Aranjuez" de Gregorio Hernández de Velasco, que Argote de Molina publicó en 1582 en su Libro de la montería (atribuyéndosela a Luis Gómez de Tapia). Véase J. Forradellas Figueras (ed.), Cartapacio poético del Colegio de Cuenca, Salamanca, 1986, pp. 42-45 y 189-205. (Dice Forradellas que "la raíz más cercana" del poema de Hernández de Velasco "está en las Selve d'amore de Lorenzo de' Medici y fundamentalmente en la segunda de ellas".)

${ }^{4} \mathrm{El}$ "Índice" de Aldrete comienza con quince poemas que (salvo tres) están en efecto en metro de silva, pero me parece digno de atención el hecho de que en seguida hay un grupo compacto de cinco poemas en metro de canción. Observa Rocha (p. 43) que "un mismo poema puede figurar en un manuscrito o impreso como silva mientras que en otro, u otros, se le llama madrigal, canción o idilio". En el autorizadísimo ms. de Nápoles hay dos silvas de Quevedo de menos de 20 versos, de manera que Asensio prefiere llamarlos madrigales. Evidentemente, la terminología era fluctuante. He aquí unos ejemplos: Polo de Medina, en Academias del jardín (1630), tiene un madrigal de 18 versos seguido de otro de 22 y de una silva de 25; los madrigales de Mira de Mescua que se leen en BAE, t. 42, pp. 423-424 son en realidad una silva hecha y derecha; $y$ a fines del siglo, el bogotano Francisco Álvarez de Velasco pone rótulo de madrigal a tres silvas (Rhythmica sacra, ed. Bogotá, 1989, pp. 62, 425 y 460). 
composiciones que menciono en el citado artículo, pp. 26-27, entre las cuales figura de manera muy prominente el Sermón estoico de censura moral (“;Oh corvas almas! ¡Oh facinorosos...!”), la silva de más altos vuelos que escribió Quevedo, y la más larga: 388 versos.

En el cap. 3 estudia Rocha las "Características de las Silvas [de Quevedo]", con lo cual se refiere a su hechura retórica: descripciones, transiciones, apóstrofes, expresiones de encomio y vituperio, irrupción de sentencias epigramáticas, etc. (predomina en ellas un tono razonador, cuasi-silogístico); pero acerca de la versificación no dice nada. De las 37 composiciones del "Índice" de Aldrete, sólo 22 son silvas métricas (cuento como tal "El instrumento artífice de muros...”, pseudo-canción pindárica); las 15 restantes están en otros metros: canción, sexta rima, octavas, tercetos, quintillas y romance. Lo primero que salta a la vista en las silvas métricas, sobre todo si se toman las Soledades como punto de comparación, es su simpleza, su falta de complejidad en la distribución de las rimas. (Cuatro de los poemas editados por Rocha son silvas métricas; el otro, A una nave, está en sexta rima.)

En el cap. 4, "Fuentes y textos de las silvas", se describen uno por uno los manuscritos e impresos en que hay textos de las consabidas 37 "silvas". Las fuentes más importantes son el ms. de Nápoles, de autoridad excepcional, y Las tres Musas impresas en 1670. Tras describir cada fuente enumera Rocha las silvas que contiene, con la simple indicación del primer verso ${ }^{5}$; compara después las distintas fuentes para encontrar su interrelación, y al final (p. 107) presenta un "Stemma provisional de todas las fuentes textuales", a partir de un origen hipotético. Rocha sabe bien que este stemma es "provisional". Para llegar al definitivo habría que comparar no un número limitado de variantes textuales (como ella hace), sino todas. Pero esto, naturalmente se llevaría mucho tiempo ${ }^{6}$.

${ }^{5}$ Hay ciertas discrepancias entre los datos de estas descripciones y el cuadro final (p. 253), donde parecen haberse colado errores: en la columna Nápoles hay que añadir "El instrumento artífice de muros"; en Évora, añadir "Al pincel”; en $B N M$ 4117, añadir "Al jabalî"; en Antequera, añadir "Al que cavaba una mina" y suprimir "Farmaceutria"; en LTM, suprimir "A una tórtola"; y en Parnaso, suprimir "A un ramo" y "Al pincel".

${ }^{6}$ Rocha no dice nada de las dos versiones de la silva "El escarmiento", incluidas ambas en Las tres Musas, con grandes diferencias entre sí (en una comienza "Oh tú que con dudoso paso mides...", y en la otra "Oh tú que inadvertido peregrinas...”). Para Astrana Marín, la primera es la definitiva; para Blecua, la segunda. Rocha se limita a indicar los manuscritos en que una y otra figuran. Tampoco dice nada de la silva "A la Calamidad", que está en Las tres Musas con un texto que era, para Astrana, el único conocido "de este fragmento de poesía”, pero que, como 
En la p. 78 hace constar Rocha que tres de las fuentes no han sido "consultadas directamente" por ella, a saber: el ms. de la biblioteca Colombina, el que fue de Sancho Rayón y el Cancionero antequerano. Esto es desafortunado, pues un conocimiento directo habría hecho más sólida la comparación, tanto más cuanto que cuatro de las Cinco silvas a cuya edición dedica ella el resto del libro (pp. 109-249) figuran en una o más de esas tres fuentes. Ella las toma en cuenta en el stemma provisional de la p. 107, y también en el aparato crítico de cada una de las silvas, pero de manera incompleta ${ }^{7}$, lo cual deja una niebla de "provisionalidad" sobre su labor.

Las cinco silvas van precedidas de sendas introducciones cuyo objeto principal es establecer, tras una minuciosa comparación de las variantes, el stemma de las fuentes respectivas. La edición de las cuatro primeras silvas está hecha a dos columnas. En dos casos ( A la Soberbia y Al que cavaba una mina) cada columna contiene, íntegra, una versión distinta; en los otros dos (AlSueño y Roma antigua y moderna)

ahora sabemos, está también en el ms. de Nápoles. Aunque aquí comienza "Oh del cielo venida" (y no "Oh tú del cielo para mí venida", como en La tres Musas), el texto es muy parecido, y deja en efecto la impresión de ser un "fragmento"; parece faltar algún desarrollo, y sobre todo una conclusión, un apóstrofe final.

${ }^{7}$ Rocha conoce el ms. de la Colombina a través de Astrana y de Blecua, cuyas noticias se contradicen (cf. p. 86, nota 19), y el ms. Rayón sólo a través de Astrana, cuyas noticias son imprecisas (por ejemplo, en la silva Al Sueño, la variante que da para el v. 35 no se sabe si procede del ms. Rayón o del ms. Colombina). En la edición de las silvas A la Soberbia y A una nave omite Rocha las variantes del ms. Rayón, y no sólo lo excluye del cuadro de la p. 253, sino que dice (p. 109) que es "de existencia hipotética", lo cual parece exageración. (Otra cosa es que se desconozca su paradero.) Blecua hizo bien en aprovecharlo, a través de Astrana, para los vv. 50-51 de la silva "En cárcel de metal...". - El texto que da Rocha para los vv. 15-18 de la silva Al Sueño dice así: “...que persuade la tristeza / a mis dos ojos, que nacieron antes / para llorar que para verte, sueño. / De sosiego los tienes inorantes...". Aquí el texto de Astrana, basado en el ms. Rayón y en el ms. Colombina, dice "...que nacieron antes / para llorar que para ver. Tú, Sueño, / de sosiego los tienes ignorantes", que es obviamente el bueno (pues los ojos nacieron para "ver", no para "ver al sueño"); también se lee así en las Flores de Calderón, sólo que Rodríguez Marín leyó "para llorar que para ver tu sueño" (lo cual es disparate). Parece que aquí se descuidó Rocha, pues no registra ninguna variante en el v. 17. - Por cierto, para las Flores se basa ella en la edición de Rodríguez Marín, no en el manuscrito que perteneció al Duque de Gor (Granada) y del cual se sacó la copia existente en la Bibl. Menéndez Pelayo. Pero Rodríguez Marín no siempre es fidedigno: en la silva Al Sueño, la variante ciego y frío (por ciega y fría, v. 22, en rima con día) es a todas luces errata suya; lo mismo hay que decir, en la silva Al que cavaba una mina, de la variante peregrina (por peregrino, v. 3, en rima con pino). 
la segunda columna presenta sólo los pasajes discrepantes. La edición de la quinta silva ( $A$ una nave) está hecha a cuatro columnas: en la primera se imprime el texto de las Flores de Calderón y en las demás se registran los pasajes discrepantes de tres distintas fuentes. Así, pues, en ningún caso nos hallamos ante un texto único (con variantes recogidas en notas de pie de página), sino ante varias redacciones, de las cuales suele ser difícil saber si presentan adiciones, supresiones, cambios o retoques debidos a la mano de Quevedo.

Muchas preguntas se me ocurren en cuanto a este método y la manera como se pone en práctica. Daré algunos ejemplos. En Roma antigua y moderna, v. 7, "i la que pobre dios [tuvo] en el prado", se entiende bien por qué tuvo va entre corchetes: la nota nos explica que en el ms. de Nápoles se lee trobo, que no tiene sentido. Pero no se ve por qué el v. 25 dice "i pobre i común fuego en estos llan[os]": no hay ninguna nota que explique los corchetes. Además, si se trata de enmendar errores del ms., el v. 24 debería decir "bíctima el corazón, los dioses bara[s]" (pues rima con aras). Así también, en A una nave (texto de las Flores), vv. 25-26, "¡Oh, qué [de] m[ied]os te apareja airado / con su esp[ad]a Orión y en sus centellas!”, se ve bien el porqué de los corchetes: en Flores hay dos burdas erratas ("Oh, qué medios... con su esposa Orión..."); pero no se ve el porqué de "ram[a]s", v. 4 (en Flores se lee ramos, que es perfectamente normal en el sentido de 'ramas de árbol'), ni el porqué de "pr[es] to", v. 41 (en Flores se lee pronto). Parecen correcciones gratuitas.

Me detendré un poco en la silva Al que cavaba una mina. Rocha imprime a dos columnas el texto del ms. 4117 de la B.N.M. (versión $\alpha$ ) y el del ms. de Nápoles (versión $\beta$ ). Ahora bien, si el que ella ha elegido como representante de la "primera redacción" es el de ese ms. madrileño ${ }^{8}$, no se ve por qué lo altera en varios lugares. Sir-

${ }^{8} \mathrm{El}$ v. 37, "a quien defiende apenas negra hondura", me hace dudar de que este manuscrito sea el mejor testimonio de la "primera redacción". La lección de Floresy de otros cuatro mss., "a quien defiende apenas su hondura", es a todas luces anterior, de una época en que aún se oía la $h$ aspirada en zonas castellanas (digamos hacia 1611); después (digamos hacia 1640), cuando esa $h$ había desaparecido del todo, se creyó necesario añadir el adjetivo negra para remediar lo que ya se sentía como hiato: su / (h)ondura. No es concebible el proceso contrario ("negra hondura" > "su hondura"). En la p. 172 dice Rocha que "un examen no exhaustivo de algunos poemas autógrafos parece indicar que [Quevedo no aspiraba la $h$ ]", y da cinco ejemplos (de los cuales hay que quitar hispano, cuya $h$ nunca se aspiró). Pero se le escapa un caso que me da la razón: el v. 63 de la silva $A$ una nave dice en las Flores "deja que la hondura en paz habiten", corregido así en uno de los mss. de Moñino: "dexa que en paz sus campos los habiten", evidentemente por la misma razón que "su hondura" se cambió en "negra hondura". 
viéndome de los datos proporcionados por la propia editora, pongo aquí varios pasajes del manuscrito, y a continuación de cada uno las "correcciones" que ella ha introducido entre corchetes:

$7 i$ arrojóte violento, / adonde quiso a su albedrío el viento $>$ arrojóte violento, / adonde quiso el alvedrío del viento; II 16 los pensaste tener por sepultura > los llegaste a temer por sepultura; II 28 sangras las venas al metal luciente $>$ delmetal luciente; II 33 No fatigues la sierra. / Dexa en paz los secretos de la tierra > ¿Qué fatigas la tierra? / Dexa en paz los secretos de la sierra; II 36 las escondidas ásperas entrañas > las escondidas y ásperas entrañas; II 42 oro llamas al que es dulce desvelo / y es cuidado precioso > i peligro precioso; II 53 sus caminos borró con anchos mares > con altos mares; II 56 y que dél vas triunfante $>$ i que vas dél triunfante; II 70 si añadirá a tu vida ese tesoro $>$ a tu vida $t u$ tesoro; II 76 mira que sacas gusto a tu heredero $>v e$ que sacas consuelo a tu heredero; II 86 o te le ha de quitar la sepultura $>$ la muerte dura.

Como puede verse -sobre todo, claro, si se tiene esta silva ante los ojos-, las "correcciones" son gratuitas. Y para ninguna veo justificación. Me pregunto por qué Rocha no imprimió simplemente el texto del ms. 4117 explicando en nota, por ejemplo en " $i$ arrojóte violento", que en otras fuentes falta la conjunción copulativa. El texto del ms., tal cual, no sólo hace buen sentido, sino que a veces puede considerarse mejor que el "corregido".

Creo necesario insistir en esto del "sentido". He aquí un pasaje de Al que cavaba una mina según la edición de Blecua (vv. 54-60):

Doy que a tu patria vuelvas al instante

que el Occidente dejas saqueado,

y que dél vas triunfante;

doy que el mar sosegado

debajo del precioso peso gime

cuando sus fuerzas líquidas oprime

[la soberbia y el peso del dinero];

doy que te sirva el viento lisonjero...

Ese verso que Blecua imprime entre corchetes (y Astrana sin ellos) hace falta no sólo para el sentido - ahí se encuentra nada menos que el sujeto de oprime-, sino también para la rima. La editora debió haberlo incluido entre corchetes, tal como hace con el v. 77, que también falta en el ms. 4117.

El v. 62 dice en la versión $\alpha$ "doy que respete el cáñamo i las velas" (se refiere al viento), y en la versión $\beta$ “doy que respeta el cá- 
ñamo a las velas", lo cual no tiene sentido. Dice Rocha (p. 173): "La enmienda de $T$ [=Las tres Musas] trata de resolver esta incongruencia: «(el viento) te respeta el cáñamo a las velas» ${ }^{9} \mathrm{o}$, dicho de otro modo, «el viento respeta el material de las velas y no las destruye»", interpretación que parece muy forzada. En cuanto al texto de la versión $\alpha$, comenta Rocha: "es probablemente la [lectura] más cercana al original”. Yo diría: es la que hace sentido, o sea la única buena. Y no veo que el verso resulte "difícil de interpretar" a causa de la frecuente sinonimia "poética" de cáñamoy velas, pues cáñamo, aquí, perfectamente puede referirse al 'cordaje', a las 'jarcias'.

Un ejemplo más: "buscas riqueza", dice el v. 78 en la versión $\alpha$, "para premiar deseos de tu muerte", y en la versión $\beta$ "para comprar deseos de tu muerte". Comenta Rocha (p. 179): "El verbo premiar expresa la idea de que será la muerte, y no él [el que cava la mina], quien recibirá la recompensa por sus esfuerzos; comprar agrega, además, la sugerencia de que, con su trabajo y sus desvelos, él está pagando por algo de que disfrutará la muerte”. Según yo, la explicación es otra, mucho más simple, y más de acuerdo con el sentido: los "deseos" no son de la muerte, sino del heredero mencionado en el v. 76: lo que desean los presuntos herederos es que el ricachón se muera lo antes posible. Tan expresivo es comprar como premiar.

De ninguna manera pretendo descalificar el largo y paciente trabajo que supone el presente libro. Lo que quiero es colaborar con la autora, esperando que estas pocas observaciones sirvan de algo para la "edición monumental" de la obra poética de Quevedo.

Antonio Alatorre

El Colegio de México

${ }^{9}$ Según nota de la p. 189, lo que se lee en Las tres Musas es "doy, que te respeta el cáñamo a tus velas". ¿Sic? ¿12 sílabas? 